\title{
Condensation reactions of a first generation of dendritic monomer
}

\author{
Alejandra Halabi, ${ }^{a}$ Pablo Froimowicz, ${ }^{\mathrm{a}}$ Marisa Martinelli, ${ }^{\mathrm{a}}$ Miriam C. Strumia, ${ }^{\mathrm{a}}$ \\ and Bernabé L. Rivas ${ }^{b}$ \\ ${ }^{a}$ Departamento de Química Orgánica - Facultad de Ciencias Químicas, \\ Universidad Nacional de Córdoba. Ciudad Universitaria, (5000) Córdoba, Argentina \\ ${ }^{b}$ Departamento de Polímeros. Facultad de Ciencias Químicas, Universidad de Concepción, \\ Casilla160-C, Concepción, Chile \\ E-mail:mcs@dqo.fcq.unc.edu.ar
}

\section{Dedicated to Professor Roberto Rossi and Edmundo Rúveda on their birthdays}

(received 07 Sep 03; accepted 24 Oct 03; published on the web 21 Dec 03)

\begin{abstract}
In this paper we report the condensation reaction of the first generation of a dendritic monomer bearing hydroxyl or amine functional groups, with dialdehydes and diisocyanate co-monomers. Dimers and crosslinked polymers were obtained by reaction with glyoxal (Gly) and glutaraldehyde (Glu), respectively. Only crosslinked polymers were found when toluene diisocyanate (TDI) was used as co-monomers. The products were characterized by FT-IR and ${ }^{1} \mathrm{H}$ NMR spectroscopy, DSC, TGA and GPC. Two principal factors exerted influence on the condensation reactions: the availability of the functional groups of the dendritic molecule and the reactivity and size of the co-monomers.
\end{abstract}

Keywords: Dendritic monomer, condensation reaction, polyurethane

\section{Introduction}

In the last few years, the development of new synthetic materials with specific functional groups has been increasingly focused to obtain materials with controlled nanostructures.

Dendrimers are monodisperse, highly branched, multifunctional and regular structures, fairly attractive for use as nanoscopic building blocks. These structural features have aroused the interest of synthetic organic chemists, and several valuable contributions to their synthesis and characterization, have been reported over the past few years. ${ }^{1-7}$ Current studies are mainly oriented to their potential properties and applications in such diverse areas as organic chemistry, analytical chemistry, biology, medicine, materials science, pharmacology, agrochemistry, environmental chemistry and chemical engineering. ${ }^{8-11}$ 
Owing to their synthetic properties, however, the maximum size of dendrimers is limited and their shapes are, in general, restricted to globular structures. Connecting dendritic macromolecules offer the possibility to create even larger macromolecules.

We have already reported the synthesis of multiacrylic dendrimers ${ }^{12}$ and the thermal polymerization experiments using radical initiator. ${ }^{13,14}$ Homopolymerization of the first generation monomers yielded up to $50 \%$ of gel fraction, while the polymerization of the second generation yielded $90 \%$ of insoluble product. However, it has been known that these kinds of macromonomers, although very reactive and attractive building blocks which undergo fast photopolymerization by a radical mechanism, ${ }^{15-17}$ contain about $30 \%$ unreacted $\mathrm{C}=\mathrm{C}$ double bonds in acrylate polymer films after UV curing. Complete conversion was never obtained, especially when multifunctional monomers were used.

In this opportunity, we studied the use of dendritic monomer with hydroxyl and amine groups in the periphery capable to polymerize through condensation reactions.

Therefore, in this paper we report the synthesis and characterization of the first generation of a dendritic monomer (1) and their copolymerization with dialdehydes and diisocyanate comonomers. New materials with potentially significant and scarcely explored properties may be attained from these novel monomers. ${ }^{18-21}$

\section{Results and Discussion}

\section{I) Synthesis of monomers}

The core of the monomers was synthesized following the strategy proposed by Newkome et al ${ }^{.22}$ which is based on the pentaerythritol 2 and acrylonitrile reaction. (see Figure 1). After methanolysis of cyano groups of $\mathbf{3}$ and hydrolysis of methyl ester $\mathbf{4}$ to generate a tetraacid molecule 5, a convergent synthesis was carried out activating the acid groups with 1,1'carbonyldiimidazole (CDI) prior to their use, allowing them to react with the protected hydroxylamine 8 in THF. A complex mixture of amide and ester products in $\mathbf{1}$ could be obtained and the ratio depended on the reaction conditions. An increase in reaction time, temperature and concentration of the initial reagents led to a rise in the amide percentage. These variations may be explained by the attack of a hydroxyl group which is favored because it is less hindered, followed by an intramolecular rearrangement by attack of the amine at the ester carbonyl to yield amide. Optimal conditions for the synthesis of product 1 were studied as previously reported ${ }^{7}$.

Therefore, dendritic monomer 1 with yields ranging from 60 to $70 \%$ was obtained and characterized by spectroscopic studies, and elemental analysis. 


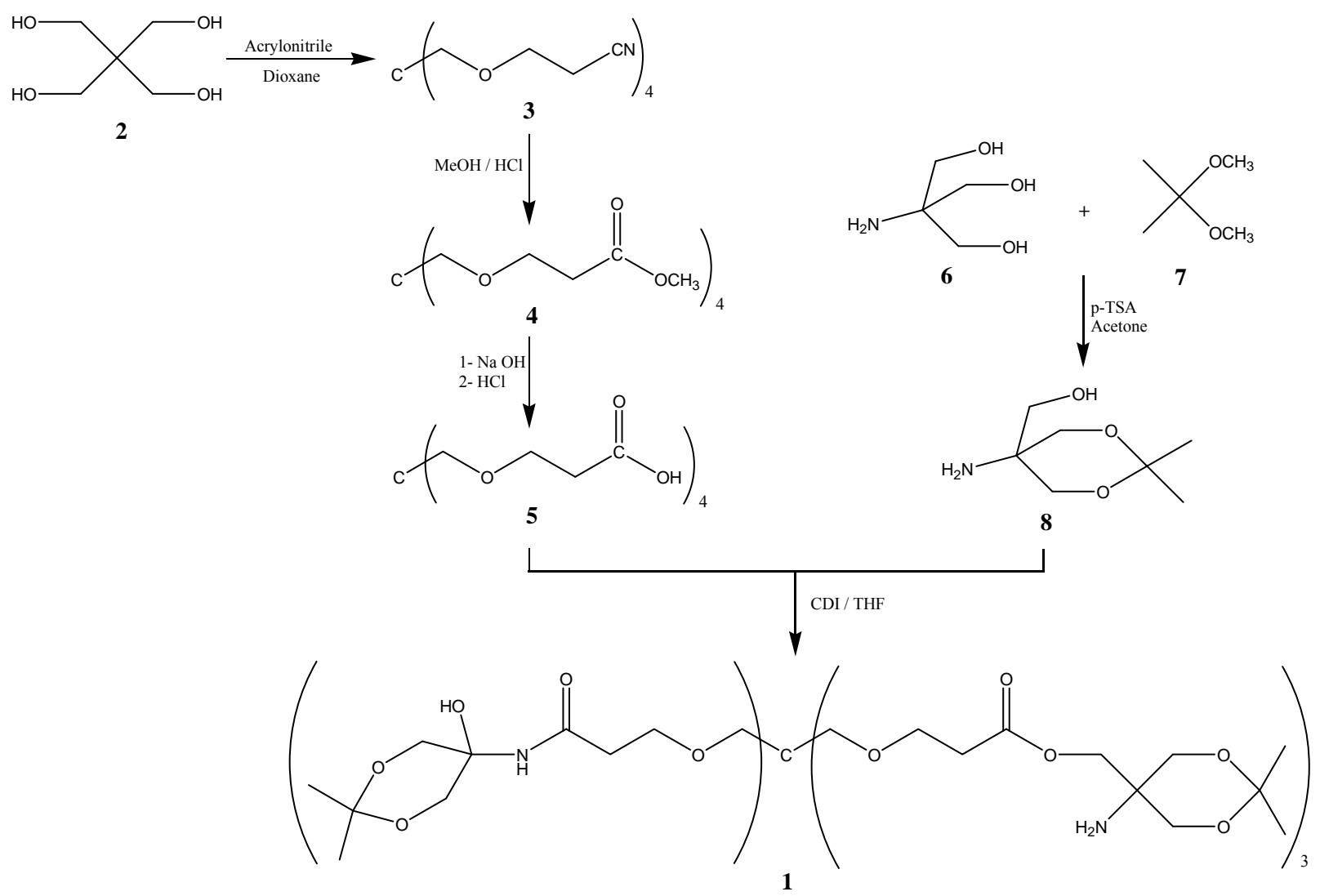

Idealized structure

Figure 1. Synthetic pathway to dendritic monomer 1.

\section{Condensation reactions}

General scheme of the condensation reactions are shown in Figure 2.

First, the reaction of the dendritic monomers was studied using dialdehydes as co-monomers.

The experiments were carried out at room temperature, in acid catalyzed aqueous solution, in a $1: 1$ equivalent ratio.

When glyoxal was used as reagent, only soluble products were found, whereas when glutaraldehyde was used, soluble products and $13 \%$ of insoluble product, 1-GLU-P, were found after $2 \mathrm{~h}$ of reaction. Increasing the reaction time to $15 \mathrm{~h}$ did not increase the amount of insoluble product. This could be attributed to the decomposition of the acetonide and a partial hydrolysis of the ester. Since the ketonic protection would be lost, the aldehydes could generate acetals, thus it could complicate the course of the condensation reaction.

The soluble fractions were analyzed by GPC in THF, revealing dimers 1-GLY-D (68\%), and monomer plus glyoxal (no dimers), 1-GLY (32\%) for the products of reaction with glyoxal, while the soluble products by glutaraldehyde reactions were monomer plus GLU, 1-GLU (82\%) when the reaction time was $2 \mathrm{~h}$ and dimers, 1-GLU-D (39\%) and monomer plus GLU, 1-GLU $(58 \%)$ with $15 \mathrm{~h}$ of reaction time. The results are shown in Table 1. 


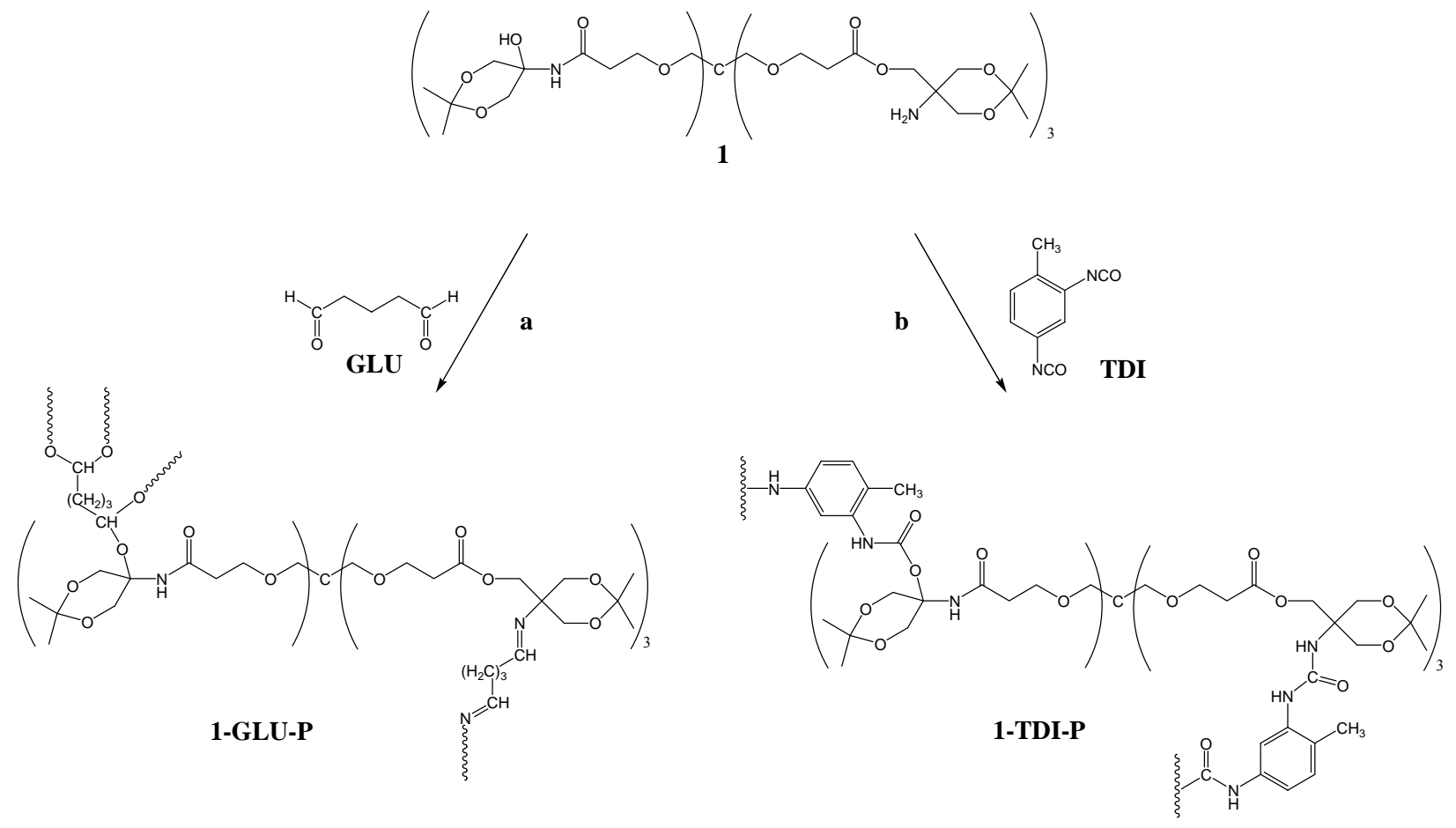

Figure 2. Condensation reactions of dendritic monomer 1 and co-monomers.

Table 1. GPC of soluble products from glyoxal and glutaraldehyde reactions

\begin{tabular}{cccc}
\hline & Wt. (theor.) & Wt. (exp.) & $(\%)$ \\
\hline Dendrimer $\mathbf{1}$ & 996 & 930 & 100 \\
Co-monomer & & & \\
Glutaraldehyde & $1096(1-\mathrm{GLU})^{\mathrm{a}}$ & 1026 & 52 \\
& $1096(1-\mathrm{GLU})^{\mathrm{b}}$ & 1021 & 58 \\
& $2092(1-\mathrm{GLU}-\mathrm{D})^{\mathrm{b}}$ & 1886 & 39 \\
Glyoxal & $1054(1-\mathrm{GLY})^{\mathrm{a}}$ & 1077 & 32 \\
& $2050(1-\mathrm{GLY}-\mathrm{D})^{\mathrm{a}}$ & 2047 & 68 \\
\hline
\end{tabular}

${ }^{\mathrm{a}}$ Reaction time of $2 \mathrm{~h},{ }^{\mathrm{b}}$ Reaction time of $15 \mathrm{~h}$.

These results demonstrated that the reactivity of the dendritic monomers with dialdehydes in those conditions was not enough to render polymer with high molecular weight in good yields, but might be improved with the incorporation of more reactive co-monomers. Meanwhile, when using a diisocyanate co-monomer, the high reactivity of these groups was capable to overcome the problem of the steric hindrance of the superficial functional groups. Therefore, a new set of experiments with toluene diisocyanate (TDI) was designed.

These reactions were performed at room temperature without catalyst, in a 1:1 equivalent ratio, either in THF solution or in bulk. 
Reactions in bulk were completed after $15 \mathrm{~h}$, while in solution it took $24 \mathrm{~h}$ for completion. Products obtained by bulk and solution experiments yielded higher than $90 \%$ of insoluble products, 1-TDI-P for both cases. The soluble products found were monomers and TDI (10\%).

The products of bulk reaction were glassy and transparent (non-swellable), while those obtained from solution reaction incorporated the solvent into the network, acquiring thus a gel appearance.

\section{Characterization of insoluble products}

The insoluble product 1-GLU-P was only studied by TGA and 1-TDI-P was characterized by TGA, DSC, FT-IR and their swelling behaviour in different solvents was tested.

Thermal stability studies (TGA) under nitrogen showed similar degradation profiles (see Table 2) and products slightly more stable up to $250^{\circ} \mathrm{C}$ when using GLU co-monomer instead of TDI.

Table 2. Thermogravimetric Studies (TGA) of insoluble condensation products

\begin{tabular}{cccccc}
\hline \multicolumn{5}{c}{ Residue $(\% \mathrm{~W})$} \\
\hline $1^{-}$- GLU-P & $100^{\circ} \mathrm{C}$ & $200^{\circ} \mathrm{C}$ & $300^{\circ} \mathrm{C}$ & $400^{\circ} \mathrm{C}$ & $500^{\circ} \mathrm{C}$ \\
$1-$ TDI-P $^{\text {a) }}$ & 93 & 75 & 46 & 34 & 18 \\
$1-$ TDI-P & 98 & 84 & 36 & 25 & 15 \\
\hline
\end{tabular}

${ }^{\mathrm{a}}$ solution polymerization; ${ }^{\mathrm{b}}$ bulk polymerization.

Differential Scanning Calorimetric experiments (DSC) performed on 1-TDI-P products, showed two endothermic transitions beginning at 170 and $250{ }^{\circ} \mathrm{C}$, which match a mass loss of the fastest rate of weight loss in TGA curve. Both transitions could be explained by the presence of two degradation processes; the first could be ascribed to a network degradation and the second to degradation of inner bonds of the dendritic monomers.

Swelling results are shown in Table 3, where it can be observed that the solutionpolymerization products swell better in less polar solvents, while the bulk-polymerization products incorporate very little solvent into the crosslinked matrix.

Table 3. Swelling behaviour for [dendrimer-TDI] products

\begin{tabular}{|c|c|c|}
\hline & Solution reaction products & Bulk reaction products \\
\hline & \multicolumn{2}{|c|}{$\% \mathrm{~S}=\mathrm{Ws}-\mathrm{Wd} / \mathrm{Wd}^{\text {a) }}$} \\
\hline $\mathrm{CHCl}_{3}$ & 109 & 63 \\
\hline $\mathrm{THF}$ & 56 & 29 \\
\hline $\mathrm{CH}_{3} \mathrm{OH}$ & 26 & 21 \\
\hline
\end{tabular}

${ }^{\mathrm{a}} \mathrm{Wd}=$ dry weight; Ws = swollen weight. 
Both products showed a swellably behavior more hydrophobic than hydrophilic. The soluble products were slowly studied by GPC.

Products 1-TDI-P were characterized by FT-IR spectroscopy, and a complete disappearance of isocyanate group $\left(v \mathrm{NCO}, 2275-2240 \mathrm{~cm}^{-1}\right)$ together with an increment in the number and intensity of the peaks between $1800-1500 \mathrm{~cm}^{-1}$, due to the formation of ureas (RNHCONHR, $v$ $1660 \mathrm{~cm}^{-1}$ ), urethane (NHCOOR, 1735-1700 $\mathrm{cm}^{-1}$ ), and allophanates (RNHCONR'COOR', 1690$\left.1732 \mathrm{~cm}^{-1}\right)^{16}$, could be noticed.

Comparative spectra of 1 and 1-TDI-P are shown in Figure 3.

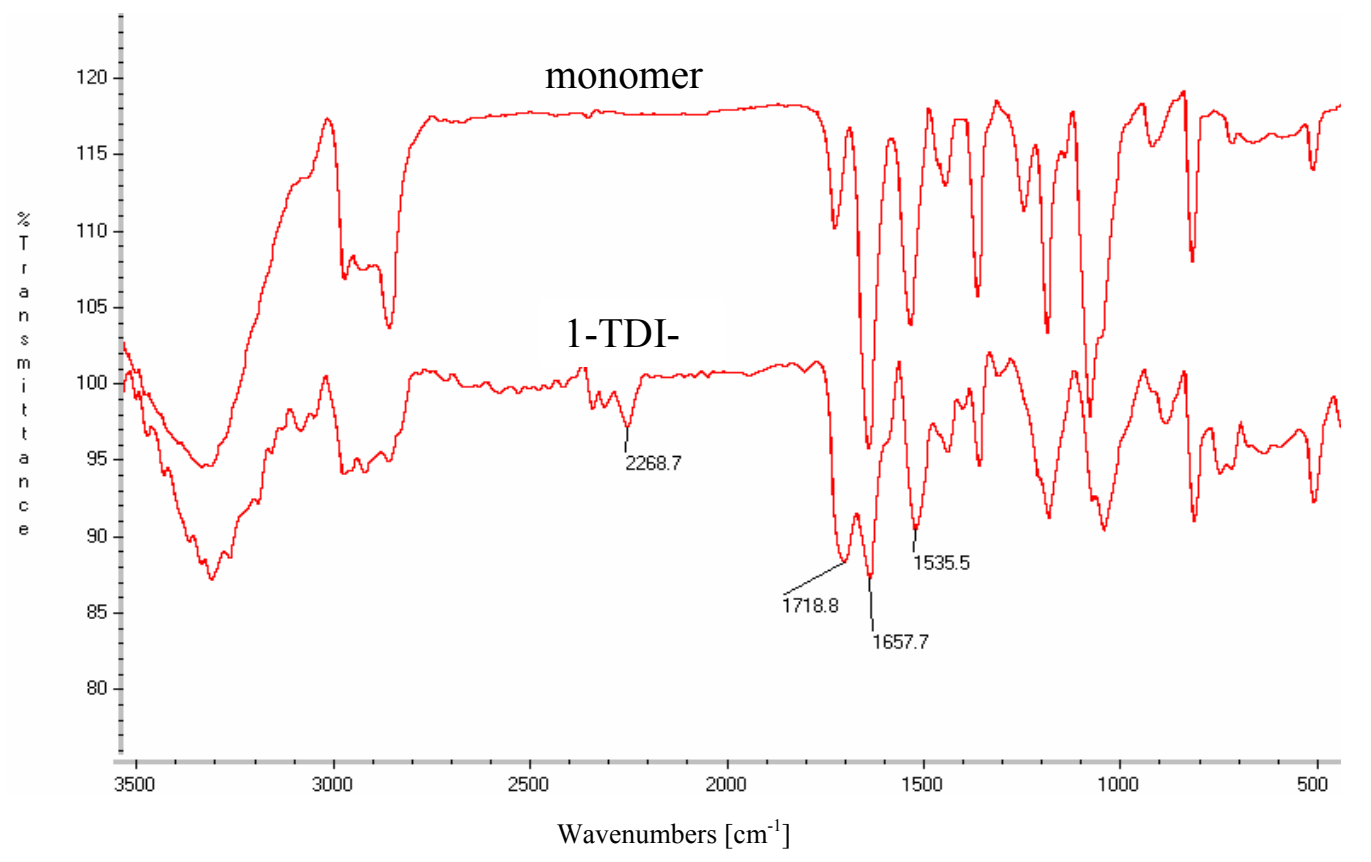

Figure 3. Comparative FT-IR spectra of dendritic monomer 1 and 1-TDI-P.

\section{Conclusions}

There are two principal factors that exert influence on the condensation reaction of the system studied in this paper: the availability of the functional groups of the dendritic molecule and the reactivity and size of the co-monomers used.

Dendritic molecule 1 possesses four functional groups, one for each arm, which are potentially available for condensation reaction with adequate co-monomers. Nevertheless, they did not show similar reactivity front diisocyanates and dialdehydes. When the latter were used, no products with high molecular weight were found in good yields, probably due to steric hindrance. 
Besides, when the more reactive co-monomer is used (TDI) and major is the length between the functional groups in the co-monomer (GLU vs. GLY), the yield of polycondensation products increased.

\section{Experimental Section}

General Procedures. Pentaerythritol was obtained from Riedel de Häen, acrylonitrile from Carlo Erba, tris (hydroxymethyl)-aminomethane (TRIS) from Anedra, 2,2-dimethoxypropane (DMP) from Aldrich, silica gel 60 from Merck, anhydrous $\mathrm{K}_{2} \mathrm{CO}_{3}$ and $\mathrm{NaOH}$ from Cicarelli, $\mathrm{CDCl}_{3}$ and $\mathrm{D}_{2} \mathrm{O}$ from Aldrich. All chemicals were used without purification. Solvents were obtained from Sintorgan purified by distillation and when necessary anhydrated and kept in $4 \AA$ molecular sieves. All dialdehydes and diisocianate were purchased and used as received.

Calorimetric experiments were conducted on a Hi-Res Modulated TGA 2950, Thermogravimetric Analyser and TA Instruments 2920, Modulated Differential Scanning Calorimeter, at a rate of $10^{\circ} \mathrm{C} / \mathrm{min}$ under nitrogen atmosphere.

The Size Exclusion Chromatography (SEC) experiments were performed on a Perkin Elmer HPLC, poly(styrene-divinylbenzene) column, and refraction index detector, using THF as solvent $(0.5 \mathrm{~mL} / \mathrm{min})$ at $20^{\circ} \mathrm{C}$ and polystyrene as standard.

Fourier Transform Infrared Spectra (FT-IR) were performed in a Nicolet 5SXC FTIR spectrometer on $\mathrm{KBr}$ discs.

NMR spectra were obtained in $\mathrm{CDCl}_{3}$, on a Bruker $200 \mathrm{MHz}$ NMR spectrometer. Chemical shift are given in ppm using TMS as internal standard. Elemental analyses were made by Atlantic Microlab, Inc. (Norcross, Georgia, USA).

Swelling index ( $\mathrm{S} \%$ ) was measured as: $\% \mathrm{~S}=\mathrm{Ws}-\mathrm{Wd} / \mathrm{Wd}$, where

$\mathrm{Wd}=$ dry weight; Ws $=$ swollen weight.

\section{I ) Monomer Synthesis}

Tetranitrile 3. (Cyanoethylation). Polyol 2 (33.50 g, $0.25 \mathrm{~mol})$ was reacted with acrylonitrile $(194 \mathrm{~mL}, 2.95 \mathrm{~mol})$ in basic medium in $1.06 \mathrm{~L}$ of a dioxane / water mixture to favor substrate dilution. The reaction mixture was stirred for $24 \mathrm{~h}$ at room temperature. When the reaction was complete, the solvent was evaporated under vacuum, and the residue dissolved in chloroform and washed with water. The crude product was purified by liquid chromatography on silica gel using a sample/silica ratio of $1 / 20$ in a column $100 \mathrm{~cm}$ tall and $5 \mathrm{~cm}$ wide and eluted with methylene chloride/ acetone $(90 / 10 \mathrm{v} / \mathrm{v})$. Yield was $85 \%, 73.9 \mathrm{~g}(0.21 \mathrm{~mol})$ of a white solid. Melting point $\approx$ room temperature.

${ }^{13} \mathrm{C} \mathrm{NMR}\left(\mathrm{CDCI}_{3}\right) \oint(\mathrm{ppm})=118.1(\mathrm{CN}) ; 68.6\left(\mathrm{C}_{4^{\circ}} \boldsymbol{C H}_{2} \mathrm{O}\right) ; 65.7\left(\mathrm{OCH}_{2} \mathrm{CH}_{2}\right) ; 45.4\left(\boldsymbol{C}_{4^{\circ}}\right) ; 18.6$ $\left(\boldsymbol{C H}_{2} \mathrm{CN}\right) .{ }^{1} \mathrm{H}$ NMR $\left(\mathrm{CDCI}_{3}\right): \delta(\mathrm{ppm})=3.59\left(\mathrm{t}, 8 \mathrm{H}, \mathrm{OCH}_{2} \mathrm{CH}_{2}\right) ; 3.40\left(\mathrm{~s}, 8 \mathrm{H}, \mathrm{C}_{4}{ }^{\circ} \mathrm{CH} \boldsymbol{H}_{2} \mathrm{O}\right) ; 2.69(\mathrm{t}$, $\left.8 \mathrm{H}, \mathrm{CH}_{2} \mathrm{CN}\right)$. 
Tetramethylester 4 (Esterification). Tetranitrile 3 (34.50 g, $0.072 \mathrm{~mol}$ ) was dissolved in 400 $\mathrm{mL}$ of dry methanol acidified with $\mathrm{HCl}(\mathrm{g})$, and the reaction mixture was refluxed for $3 \mathrm{~h}$. After the solvent was removed under vacuum, the crude product was purified by liquid chromatography on silica gel, using a sample/silica ratio of 1/20 in a column $60 \mathrm{~cm}$ tall and 3.5 $\mathrm{cm}$ wide and eluted with methylene chloride/ acetone $(90 / 10 \mathrm{v} / \mathrm{v})$. Yield was 50\%, $17.28 \mathrm{~g}$ $(0.036 \mathrm{~mol})$ of colorless oil.

${ }^{13} \mathrm{C}$ NMR $\left(\mathrm{CDCI}_{3}\right) \delta(\mathrm{ppm})=172.0(\mathrm{COOMe}) ; 69.4\left(\mathrm{C}_{4} \cdot \mathrm{CH}_{2} \mathrm{O}\right) ; 66.7\left(\mathrm{OCH}_{2} \mathrm{CH}_{2}\right) ; 51.5$ $\left(\boldsymbol{C H}_{3}\right) ; 45.3\left(\mathrm{C}_{4}{ }^{\circ}\right) ; 34.8\left(\boldsymbol{C H}_{2} \mathrm{COOR}\right) .{ }^{1} \mathrm{H} \mathrm{NMR}\left(\mathrm{CDCl}_{3}\right) \delta(\mathrm{ppm}): 3.68\left(\mathrm{~s}, 12 \mathrm{H}, \mathrm{OCH}_{3}\right) ; 3.64(\mathrm{t}$, $\left.8 \mathrm{H}, \mathrm{OCH}_{2} \mathrm{CH}_{2}\right) ; 3.32$ ( $\left.\mathrm{s}, 8 \mathrm{H}, \mathrm{C}_{4}{ }^{\circ} \mathrm{CH}_{2} \mathrm{O}\right) ; 2.54\left(\mathrm{t}, 8 \mathrm{H}, \mathrm{CH}_{2} \mathrm{CO}_{2} \mathrm{Me}\right)$.

Tetraacid 5 (Hydrolysis of tetramethylester 4). Tetraester $4(21 \mathrm{~g}, 0.050 \mathrm{~mol})$ was mixed with $210 \mathrm{~mL}$ of an aqueous $3 \mathrm{M} \mathrm{NaOH}$ solution for $24 \mathrm{~h}$ at room temperature. When the reaction was complete, the product was acidified and extracted with ethyl ether. Yield: 75\%, $159 \mathrm{~g}(0.038$ mol) of a white solid. Mp $91-92^{\circ} \mathrm{C}$

${ }^{13} \mathrm{C}$ NMR $\left(\mathrm{D}_{2} \mathrm{O}\right) \delta(\mathrm{ppm})=176.0(\mathrm{COOH}) ; 68.7\left(\mathrm{C}_{4^{\circ}} \boldsymbol{C H}_{2} \mathrm{O}\right) ; 66.5\left(\mathrm{OCH}_{2} \mathrm{CH}_{2}\right) ; 44.7\left(\mathrm{C}_{4^{\circ}}\right) ; 34.1$ $\left(\mathrm{CH}_{2} \mathrm{COOH}\right) .{ }^{1} \mathrm{H}$ NMR $\left(\mathrm{D}_{2} \mathrm{O}\right), \delta(\mathrm{ppm})=3.59\left(\mathrm{t}, 8 \mathrm{H}, \mathrm{OCH}_{2} \mathrm{CH}_{2}\right) ; 3.33\left(\mathrm{~s}, 8 \mathrm{H}, \mathrm{C}_{4}{ }^{\circ} \mathrm{CH} \boldsymbol{H}_{2} \mathrm{O}\right) ; 2.36$ (t, $\left.8 \mathrm{H}, \mathrm{CH}_{2} \mathrm{COOH}\right)$.

Hydroxylamine 8 (Diol protection of TRIS 6). Best yields were obtained when mixing TRIS 6 $(12.7 \mathrm{~g}, 0.11 \mathrm{~mol})$ with DMP $7(41 \mathrm{~mL}, 0.33 \mathrm{~mol})$ in $300 \mathrm{~mL}$ dry acetone, and $0.5 \%(0.11 \mathrm{~mol}$, $21.0 \mathrm{~g}$ ) of $p$-TSA, during $3 \mathrm{~h}$ at room temperature. When the reaction was over, the solvent was vacuum removed and the product dissolved in water. The $\mathrm{pH}$ of aqueous solution was raised to 9 and the extraction performed with $\mathrm{CH}_{2} \mathrm{Cl}_{2}$. The product migrated into the organic phase whereas the unreacted 6 and the salt of $p$-TSA remained in the aqueous phase. Yield: $60 \%, 10.63 \mathrm{~g}(0.066$ mol). Melting point: $81-82^{\circ} \mathrm{C}$.

${ }^{13} \mathrm{C} \mathrm{NMR}\left(\mathrm{CDCI}_{3}\right) \delta(\mathrm{ppm})=97.5\left(\mathrm{O}-\mathrm{C}_{\text {acetal }}-\mathrm{CH}_{3}\right), 67.2\left(\mathrm{C}_{\text {tris }} \mathrm{CH}_{2} \mathrm{OC}_{\text {acetal }}\right), 64.8\left(\mathrm{C}_{\text {tris }} \mathrm{CH}_{2} \mathrm{OH}\right)$, $50.1\left(\boldsymbol{C}_{\text {tris }}\right), 24.8$ and $22.2\left(\boldsymbol{C H}_{3}\right) .{ }^{1} \mathrm{H}$ NMR $\left(\mathrm{CDCl}_{3}\right) \delta(\mathrm{ppm}): 3.78\left(\mathrm{~d}, 8 \mathrm{H}, \mathrm{C}_{\text {tris }}-\mathrm{CHaHb}-\mathrm{O}-\right) ; 3.52$

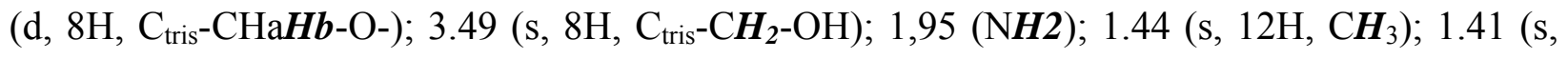
$\left.12 \mathrm{H}, \mathrm{CH}_{3}\right)$.

Dendritic monomer 1 (Esterification-Amidation of Tetraacid 5 with amine 8). Tetraacid 5, $2.53 \mathrm{~g}(0.006 \mathrm{~mol})$ was dissolved in THF and activator $1,1^{\prime}$-carbonyldiimidazol (CDI) was added in a 1:1 equivalent relation. After $45 \mathrm{~min}$. at room temperature amine 8 (1:1 equivalent ratio) was added and allowed to react to complete the reaction time. Then, the solvent was vacuum evaporated, the crude product was dissolved in chloroform and washed with water, the organic phase was dried with $\mathrm{CaCl}_{2}$. Yield: $86 \%, 5.11 \mathrm{~g}$ (0.005 mol).

FT-IR: $1735 \mathrm{~cm}^{-1}(v \mathrm{C}=\mathrm{O}$ ester $), 1660 \mathrm{~cm}^{-1}(\nu \mathrm{C}=\mathrm{O}$ amide $)$ and $1543 \mathrm{~cm}^{-1}(\sigma \mathrm{NH}$ amide $)$

${ }^{13} \mathrm{C} \mathrm{NMR}\left(\mathrm{CDCI}_{3}\right) \delta(\mathrm{ppm})=171.8(\boldsymbol{C O O R}) ; 165.7(\boldsymbol{C O N H}) ; 98.7\left(\mathrm{O}-\boldsymbol{C}_{\text {acetal }}-\mathrm{CH}_{3}\right), 69.2\left(\mathrm{C}_{4^{\circ}}\right.$ $\left.\mathrm{CH}_{2} \mathrm{O}\right) ; 66.8\left(\mathrm{OCH}_{2} \mathrm{CH}_{2}\right) ; 63.5\left(\mathrm{C}_{\text {tris }} \mathrm{CH}_{2} \mathrm{OC}_{\text {acetal }}\right), 62.2\left(\mathrm{C}_{\text {tris }} \mathrm{CH}_{2} \mathrm{OH}\right), 53.2\left(\mathrm{C}_{\text {tris }}\right), 44.5\left(\mathrm{C}_{4^{\circ}}\right) ; 35.0$ $\left(\boldsymbol{C H}_{2} \mathrm{COOR}\right) ; 23.3$ and $22.1\left(\boldsymbol{C H}_{3}\right) .{ }^{1} \mathrm{H} \mathrm{NMR}\left(\mathrm{CDCI}_{3}\right), \delta(\mathrm{ppm}): 4.12\left(\mathrm{~s}, 8 \mathrm{H}, \mathrm{C}_{\text {tris }} \mathrm{CH}_{2} \mathrm{OCOR}\right)$; 3.77 (d, 8H, C tris $-\mathrm{CHaHb}-\mathrm{O}-$ ); 3.65 (t, 8H, OCH $\mathrm{CH}_{2}$ ); 3.55 (d, 8H, C tris $\left.-\mathrm{CHaHb}-\mathrm{O}-\right)$; 3.31 (s, $8 \mathrm{H}, \mathrm{C}_{4}{ }^{\circ} \mathrm{CH}_{2} \mathrm{O}$ ); 2.58 (t, $\mathrm{C}_{\text {tris }} \mathrm{CH}_{2} \mathrm{OCOR}$ ); 2.47 (t, $\left.\mathrm{CONHC}_{\text {tris }} \mathrm{CH}_{2} \mathrm{OH}\right) ; 1,95$ (NH2); 1.44 (s, 12H, 
$\left.\mathrm{CH}_{3}\right) ; 1.41$ (s, 12H, CH$\left.{ }_{3}\right) . \mathrm{C}_{45} \mathrm{H}_{80} \mathrm{~N}_{4} \mathrm{O}_{20}$ (997.29): Calcd. C 54.19; H 8.10; N 5.62; O 32.09. Found: C 54.98; H 8.31; N 4.81; O 31.90.

\section{II) Condensation reactions}

Reactions were carried out using dendritic monomer 1 with dialdehydes (glutaraldehyde (GLU) and glyoxal (GLY)) in aqueous solution ([monomer] $=0.3 \mathrm{M})$. They were acid catalyzed $(\mathrm{HCl} 0.4 \%)$ and at room temperature, in 1: 1 equivalent ratio, during 2 and $15 \mathrm{~h}$. After the reaction time, the water was vacuum evaporated and the residue washed with chloroform, and the soluble and insoluble products separated.

Some experiments with toluendiisocyanate (TDI) were carried out in THF solution $([$ monomer $]=0.3 \mathrm{M})$ while others were performed in bulk. All experiments were conducted under nitrogen atmosphere, without catalyst, and 1:1 equivalent ratio. Previously, the monomer 1 was dried in a vacuum dessicator at $30^{\circ} \mathrm{C}$ for $24 \mathrm{~h}$. The reactions were followed by the disappearance of isocyanate groups $\left(2270-2240 \mathrm{~cm}^{-1}\right)$ using FT-IR spectroscopy.

\section{Acknowledgments}

The authors gratefully thank to FONCyT, CYTED and SECyT for financial support and to CONICET and FOMEC for the fellowship to Lic. P. Froimowicz and Dr. A. Halabi, respectively.

\section{References}

1. Newkome, G. R., Moorefield, C.N., Vogtle, F. Dendritic Molecules: Concepts, Synthesis, Perspectives; VCH: Weinheim, 1996.

2. Tomalia, D.; Frechet, J. Polym. Sci.: Part A: Polym. Chem. 2002, 101, 12, 3819.

3. Grayson, S.; Frechet, J. J. Chem. Rev. 1997, 97, 1681.

4. Bosman, A.W.; Jansen, H.M.; Meijer, E.W. Chem. Rev. 1999, 99, 1665.

5. Zeng, F.; Zimmerman, S.C. Chem. Rev., 1997, 97, 1681.

6. Percec, V.; Ahn, C.; Cho, W.; Jamieson, A.; Kim, J.; Leman, T.; Schmidt, M.; Gerle, M.; Moller, M.; Prokhorova, S.; Cheng, S.; Zhang, A.; Ungar, G.; Yerdley, J. J.Chem. Soc. 1998, $120,34,8619$.

7. Matyjaszewski, K.; Shigemoto, T.; Frechet, J.; Leduc, M. Macromolecules 1996, 29, 12 , 4167.

8. Peerlings, H.W.; Van Benthem, R.A.T.M.; Meijer, E.W. J. Polym. Sci.: Part A: Polym. Chem. 2001, 39, 3112.

9. Kim, C.; Kim, H. J. Polym. Sci.: Part A: Polym. Chem. 2002, 40, 326. 
10. Vogtle, F.; Gestermann, S.; Hesse, H.; Schwierz, B.; Windisch, B. Progress Polym. Sci. 2000, 25, 987.

11. Vetter, S.; Koch, S.; Schluter, A. J. Polym. Sci.: Part A 2001, 59, 1940.

12. Halabi. A.; Strumia, S.C. J. Org. Chem. 2000, 29, 9210.

13. Halabi, A. Synthesis of Polymeric Support from Dendritic Molecules. Doctoral Thesis Universidad Nacional de Córdoba. 2000, Argentina.

14. Halabi, A.; Froimowicz, P.; Strumia, M.C. Polymer Bull. 2002. In press.

15. Shi, W.; Ramby, B. J. Appl. Polym. Sci. 1996, 59, 1937.

16. Shi, W.; Ramby, B. J. Appl. Polym. Sci. 1996, 59, 1945.

17. Shi, W.; Ramby, B. J. Appl. Polym. Sci. 1996, 59, 1951.

18. Tsukruk, V.V. Prog. Polym. Sci. 1997, 22, 247.

19. Holger, F. Angew. Chem. Int. Ed. 1998, 37, 2193.

20. Ingerl, A.; Neubert, I.; Klopsch, R.; Schluter, D. Eur.J. Org. Chem. 1998, 2553.

21. Schluter, D. Topics Current Chem. 1998, 197, 165.

22. Newkome, G.R.; Lin, X. Macromolecules 1991, 24, 1443.

23. David, D.J.; Staley, H.B. J. In Analytical Chemistry of the Polyurethanes. Part III; Krieger, R. E. Eds.; Publishing Company: NY, 1979; Vol. XVI, p 197. 